\title{
Functional Physical Fitness and Anthropometric Characteristics of Older Women Living in Different Environments in Southwest Poland
}

\author{
Antonina Kaczorowska ${ }^{1}$ (D) Małgorzata Fortuna ${ }^{2}$ (D) $\cdot$ Aleksandra Katan $^{3}$ (D) \\ Agnieszka Kaczorowska ${ }^{4}$ (D) Zofia Ignasiak ${ }^{5}$ (D)
}

Accepted: 4 December 2021 / Published online: 30 December 2021

(c) The Author(s) 2021

\section{Introduction}

Demographic and scientific research shows that the percentage of older adults ( $\geq 60$ years of age) is significantly increasing in industrialized countries (Central Statistical Office, 2016; Marques et al., 2014). The percentage of older adults in Poland's population increased from $14.7 \%$ in 1989 to $22.2 \%$ in 2014 , and is projected to further increase to $>40 \%$ by 2050 (Central Statistical Office, 2016). A more complete interpretation of life expectancy data is made possible by analyzing older adults in relation to their health. The average healthy life expectancy index for men and women aged 65 years in Poland is $46 \%$ (7.2 remaining years of life) and $39 \%$ (7.8 remaining years of life) respectively. In European Union

Antonina Kaczorowska

antonina.kaczorowska@uni.opole.pl

Małgorzata Fortuna

fortun@o2.pl

Aleksandra Katan

akatan@wp.pl

Agnieszka Kaczorowska

aggnieszka17@gmail.com

Zofia Ignasiak

zofia.ignasiak@awf.wroc.pl

1 Institute of Health Sciences, University of Opole, ul. Katowicka 68, 45-060 Opole, Poland

2 Faculty of Natural Sciences and Technology, The Karkonosze University of Applied Sciences in Jelenia Góra, Jelenia Góra, Poland

3 Faculty of Education, Business and Engineering, College of Management and Entreprise in Wałbrzych, Wałbrzych, Poland

4 Department of Physiotherapy, University School of Physical Education in Wrocław, Wrocław, Poland

5 Department of Biostructure, University School of Physical Education in Wrocław, Wrocław, Poland 
(EU) countries this index is higher, with values of 10.3 remaining years of life for men, and 10.4 remaining years of life for women (Central Statistical Office, 2016). The population structure in Poland is diverse. In the Dolnośląskie and Opolskie provinces, located in southwest Poland, the population is characterized by a greater percentage of elderly people in post-working age, compared to the population of Poland as a whole. Moreover the Opolskie province is characterized by decreasing population (Central Statistical Office, 2021). Based on this previous research, it seems important to analyze the aging process in terms of factors that can affect the maintenance and duration of functional independence and health in older adults. When analyzing the aging process, attention should be paid to the situation of older women. Women live longer than men, but more often suffer from chronic diseases and disabilities (Central Statistical Office, 2016; Gaigaliene, 2006).

An important factor in maintaining independence in older life is functional physical fitness. Functional fitness has been defined as the physiological capacity to perform normal everyday activities safely, independently, and without undue fatigue (Rikli \& Jones, 1999). The major components of functional physical fitness are lower and upper body strength, lower and upper body flexibility and mobility, aerobic fitness, and motoric coordination and dynamic balance. These components allow performance of activities required for independent living, such as household chores, walking, climbing steps, and carrying objects (Rikli \& Jones, 1999). Deficits in the major components of functional physical fitness are linked to physical disability (Maslow et al., 2011), cognitive decline (Auyeung et al., 2011), and reduced quality of life (Olivares et al., 2011) During the ageing process, a decrease in physical fitness occurs, leading to older adults experiencing difficulties with everyday activities and functioning. Older adults experience decreases in muscular strength and stamina, agility, joint mobility (Milanović et al., 2013), and aerobic capacity. The number of falls in older adults increases as a consequence of reduced muscular strength and decreased balance (São Romão Preto et al., 2015). The decline of physical fitness and performance with age is physiological and inevitable, but it proceeds at different rates in individuals. The level of an individual's physical fitness is influenced by various factors that include physical activity, nutrition, body mass and participation. General life activity and participation in society are very important items. According to International Classification of Impairments, Activities and Participation (ICIAP) the term person's functioning involves functioning on three levels: biological, personal and social (Kabsch, 2001). Participation in social life is therefore also one of the factors that maintain seniors' independence. Whereas systematic physical activity in older adults can slow the rate of decline in physical fitness and performance, limit negative health changes, and maintain the ability to perform everyday activities and functions. More specifically, physical activity can help maintain gait speed, healthy body composition, circulatory and respiratory function, and postural stability (Rava et al., 2017; Skrzek et al., 2015). Levels of physical activity and participation in society may very across country and continents due to different socio-demographic and economic conditions (Karlin \& Weil, 2017). Therefore, identifying older adults whose fitness levels are below age-related normative standards, and the recommended fitness standards needed for independent functioning, should be considered as a preventive health strategy. 
The purpose of the present study is (1) to evaluate and compare the anthropometric characteristics and functional physical fitness of Polish older women living in social assistance homes (SAH), to that of Polish older women living independently and taking classes with the University of the Third Age (U3A); (2) to compare the functional physical fitness of Polish older women to normative standards from the United States of America (USA) developed by the authors of the test, and to European standardsPortuguese and Polish percentile norms; and (3) to evaluate the functional physical fitness of Polish older women relative to criterion fitness standards associated with maintaining physical independence.

\section{Materials and Methods}

\section{Study Design and Setting}

The study was carried out from 2016 to 2019, and included 142 women from southwest Poland. The women were aged 60 to 84 years $(70.92 \pm 6.96$ years).

The research was carried out in accordance with the Declaration of Helsinki, and followed good clinical practice guidelines. The Commission of Research of the University School of Physical Education, Wrocław, Poland granted approval for the research (approval date: 2015). All participants gave written informed consent after explanation of the procedures involved.

The study is a part of larger research that was retrospectively registered on the ISRCTN platform under the number 18225729.

\section{Participants}

Participants were resident in SAH in the Dolnośląskie and Opolskie provinces $(n=70$; $\mathrm{SAH}$ group), or living independently in Dolnośląskie province and taking classes with the U3A ( $n=72$; U3A group).

To be included in the study participants were required to (1) be able to move independently and take the fitness test, (2) not have any medical impediments, (3) be able to communicate verbally, and (4) provide voluntary written consent to participate in the study. In turn, the exclusion criteria comprised (1) acute injuries and infections, (2) cancer, (3) recent myocardial infarction, (4) other medical impediments to research, (5) the lack of verbal contact and (6) lack of written consent to participate in the study.

To compare fitness levels of Polish older women, the SAH and U3A groups were further sub-divided into the following age groups: $60-64$ years, $65-69$ years, 70 -74 years, $75-79$ years, and $80-84$ years.

\section{Measurement Tools}

\section{Senior Fitness Test}

The Senior Fitness Test was used to assess participants' functional physical fitness (Rikli \& Jones, 2001). The Senior Fitness Test evaluates upper and lower 
body strength, upper and lower body flexibility and mobility, aerobic capacity, motoric coordination, and dynamic balance using the following assessments:

(1) Arm curl: Participants flex and extend the elbow joint for $30 \mathrm{~s}$ whilst holding a $5 \mathrm{lbs}(2.27 \mathrm{~kg})$ dumbbell. The number of repetitions performed in the given time is recorded, and provides an indication of upper body strength.

(2) Chair stand: From seated participants stand and return to seated for $30 \mathrm{~s}$. The number of stands from seated in the given time is recorded, and provides an indication of lower body strength.

(3) Back scratch: Participants reach with their hands behind their back, and attempt to get fingers from opposing hands to touch. The distance between the fingers (to the nearest $0.5 \mathrm{~cm}$ ) is recorded, and provides an indication of upper body flexibility and mobility.

(4) Chair sit and reach: Participants sit with one leg extended at the knee, and the other leg flexed at the knee with the foot flat on the floor. Participants reach forward and attempt to touch the toes of the extended leg. The distance between the fingers and toes (to the nearest $0.5 \mathrm{~cm}$ ) is recorded, and provides an indication of lower body flexibility and mobility.

(5) 8 foot up and go: From seated participants stand up and walk a distance of 8 feet $(2.44 \mathrm{~m})$, turn, and return to seated. The time taken to return to seated is recorded (to the nearest $1 / 100^{\text {th }} \mathrm{sec}$ ), and provides an indication of coordination and dynamic balance.

(6) 6-min walk: Participants walk as far as possible in the given time. The number of meters walked is recorded, and provides an indication of aerobic capacity.

All assessments were performed in the morning (i.e., before 12 noon). The U3A group was assessed in the Biokinetics Research Laboratory of the University School of Physical Education, Wrocław, Poland. Assessment of the SAH group took place in rehabilitation rooms in their SAH. Prior to testing participants received a demonstration of the assessments, and were taken through a warm-up protocol. Participants were instructed to try their best and achieve as good a score as possible in each assessment. The study authors collected all data.

\section{Anthropometric Characteristics}

Body height (to the nearest $0.5 \mathrm{~cm}$ ) and mass (to the nearest $0.5 \mathrm{~kg}$ ) were measured using an integrated stadiometer and scale (SECA, model 764). Subjects were dressed in light clothing, and stood barefoot, upright, and with eyes directed straight ahead when being measured. Body mass index (BMI) was calculated using participants' height (in meters) and mass measurements (mass/height ${ }^{2}$ ). Using the World Health Organization (WHO) criteria (2000), BMI was used to categorize participants (underweight: $<18.5 \mathrm{~kg} / \mathrm{m}^{2}$; normal: $18.5-24.99 \mathrm{~kg} / \mathrm{m}^{2}$; overweight: $25-29.9 \mathrm{~kg} / \mathrm{m}^{2}$; obese class I: $30-34.99 \mathrm{~kg} / \mathrm{m}^{2}$; obese class II: 35 $-39.9 \mathrm{~kg} / \mathrm{m}^{2}$; and obese class III: $\geq 40 \mathrm{~kg} / \mathrm{m}^{2}$ ). 


\section{Statistical Methods}

Descriptive statistics including mean (M), standard deviation (SD), median (Me), minimum (Min), and maximum (Max) were calculated. Normality was assessed using the Shapiro-Wilk test. Parametric methods were used to analyze the anthropometric data, with differences between mean values analyzed using the Student's t-test. Non-parametric methods were used to analyze age and functional physical fitness, with the Mann-Whitney U test used to analyze between-group differences. Analyses were carried out using Statistica (Version 13.1, StatSoft, USA), with the alpha level set at 0.05 .

Participants' results were compared with normative standards where appropriate comparative data (i.e., same age group and testing protocol) were available (Rikli \& Jones, 2002), to the Portuguese percentile norms developed by Marques et al. (2014) in four age groups ( $65-69$ years, $70-74$ years, $75-79$ years, and $80-84$ years), and to the Polish percentile norms developed by Ignasiak et al. (2020) in five age groups (65- 69 years, $70-74$ years, $75-79$ years, and $80-84$ years). In Polish norms, the results below the norm are below the 25 th percentile in the 30-s chair stand, arm curl, chair sit and reach, back scratch, and above the 75th percentile in the 8-foot up and go test. The results of four Senior Fitness Test assessments (arm curl, chair stand, 8 foot up and go, and 6 min walk) were compared to the clinically relevant fitness standards developed in the USA by Rikli and Jones (2012). These fitness standards determine the fitness level needed to maintain independence in old age. To compare fitness levels of Polish older women to USA normative standards and clinically relevant fitness standards the yards in the 6-min walk have been converted into meters.

\section{Results}

\section{Descriptive Data}

The statistical profile of age of participants is presented in Table 1. The groups did not differ in age.

The SAH and U3A groups were further sub-divided into the following age groups: $60-64$ years, $65-69$ years, $70-74$ years, $75-79$ years, and $80-84$ years. The number of participants in different age groups is presented in Table 2.

Table 1 The statistical profile of age of participants

\begin{tabular}{lllllllll}
\hline Values & Group & M & SD & Me & Min & Max & Z & $p$ \\
\hline Age & SAH & 71.68 & 8.41 & 73.00 & 60.00 & 84.00 & 1.0833 & 0.2786 \\
& U3A & 70.18 & 5.20 & 69.00 & 61.00 & 84.00 & & \\
\hline
\end{tabular}

Z-Mann-Whitney U test, $p-p$ value 
Table 2 The number of participants in different age groups

\begin{tabular}{llllll}
\hline Groups & \multicolumn{5}{l}{ Age groups } \\
\cline { 2 - 6 } & $60-64$ & $65-69$ & $70-74$ & $75-79$ & $80-84$ \\
\hline SAH & 21 & 8 & 10 & 14 & 17 \\
U3A & 6 & 32 & 20 & 9 & 5 \\
\hline
\end{tabular}

\section{Evaluation of Anthropometric Characteristics and Functional Physical Fitness of Older Women in the SAH and U3A Groups}

The older women in the U3A group were significantly heavier and taller than the older women in the SAH group. There was no significant between-group difference for BMI. BMI categorized the participants as overweight (Table 3).

Using BMI, a larger percentage of the SAH group was categorized as normal weight, and a smaller percentage of the $\mathrm{SAH}$ group was categorized as overweight compared to the U3A group. The percentage of people categorized as obese was similar in both groups. The number of participants who were categorized as underweight, obese class II, or obese class III was small (Table 4).

In all assessments of functional physical fitness the U3A group performed significantly better than the SAH group (Table 5). The U3A group was characterized by better functional physical fitness compared to the SAH group.

\section{Comparison of Polish Older Women's Fitness Levels to USA Normative Standards and to European Standards-Portuguese and Polish Percentile Norms}

The results obtained from each participant were compared with USA normative standards for their age group. In the SAH group the best performance was achieved in the arm curl, where average results in the three age groups (60-64, 65-69, 74-49 years) were within normal ranges, and the percentage of women achieving scores in the normal ranges was high. In the chair stand, only the average of the $65-69$ years group fell within the normal ranges developed by the authors of the Senior Fitness Test. In the other samples, no groups achieved scores in the normal ranges. The weakest trials were in the 8 foot up and go and 6 min

Table 3 The statistical profile of anthropometric characteristics of participants

\begin{tabular}{lllrrrrrr}
\hline Values & Group & \multicolumn{1}{l}{ M } & \multicolumn{1}{c}{ SD } & \multicolumn{1}{l}{ Me } & Min & Max & \multicolumn{1}{c}{$\mathrm{t}$} & \multicolumn{1}{c}{$p$} \\
\hline Body height [m] & SAH & 1.53 & 0.07 & 1.54 & 1.33 & 1.66 & -2.8742 & $0.0046^{*}$ \\
& U3A & 1.56 & 0.06 & 1.56 & 1.43 & 1.72 & & \\
Body mass [kg] & SAH & 66.30 & 16.04 & 66.00 & 33.50 & 105.00 & -2.3779 & $0.0187^{*}$ \\
& U3A & 71.90 & 11.76 & 70.50 & 46.00 & 105.50 & & \\
BMI [kg/m $\left.{ }^{2}\right]$ & SAH & 28.24 & 6.32 & 28.35 & 16.61 & 43.16 & -1.3703 & 0.1727 \\
& U3A & 29.49 & 4.38 & 29.12 & 18.99 & 43.30 & & \\
\hline
\end{tabular}

t—Student's t test, $p-p$ value, $* p \leq 0.05$ 
Table 4 BMI classification of participants

\begin{tabular}{lll}
\hline BMI classification \% & SAH & U3A \\
\hline Underweight & 5.71 & 0 \\
Normal range & 30.00 & 13.88 \\
Overweight & 24.28 & 47.22 \\
Obesity class I & 27.14 & 27.77 \\
Obesity class II & 10 & 9.72 \\
Obesity class III & 2.85 & 1 \\
\hline
\end{tabular}

walk, where the percentage of participants reaching the normative standards was very low or none. The U3A group performed more favorably. In the U3A group, participants achieved scores within the normal ranges across all age groups in the arm curl, chair stand, chair sit and reach, 8 foot up and go and 6-min walk. The weakest performance in the U3A group was observed in the back scratch, where only the $60-64$ years and $75-79$ years groups achieved the normative standards (Table 6).

When compared with the Portuguese percentile norms, almost all mean age group scores in the SAH group were below the $50^{\text {th }}$ percentile. Only the result of the $80-84$ years group in the arm curl was in the $50^{\text {th }}-75^{\text {th }}$ percentile range. The poorest results were in the 8 foot up and go and 6-min walk, where the average scores in the $65-69$ years and $70-74$ years groups were below the $10^{\text {th }}$ percentile, with the scores for the $75-79$ years and $80-84$ years groups in the $10^{\text {th }}-25^{\text {th }}$ and $25^{\text {th }}-50^{\text {th }}$ percentile ranges respectively. The U3A group performed better. In the arm curl, chair stand, back scratch, and chair sit and reach the mean results for all age groups were above the $50^{\text {th }}$ percentile. Poorer performance was observed in the 8 foot up and go and 6-min walk, where the average results of the $75-79$ years

Table 5 The statistical profile of the results of the Senior Fitness Test of the participants and the significance of the differences

\begin{tabular}{llrrrrrrr}
\hline Values & Group & \multicolumn{1}{l}{ M } & SD & Me & Min & Max & Z & $p$ \\
\hline Arm curl [reps] & SAH & 12.98 & 4.04 & 13.00 & 3.00 & 27.00 & -9.0239 & $<0.001^{*}$ \\
& U3A & 20.77 & 3.37 & 21.00 & 11.00 & 28.00 & & \\
Chair stand [reps] & SAH & 9.57 & 3.26 & 9.50 & 1.00 & 15.00 & -8.9619 & $<0.001^{*}$ \\
& U3A & 16.56 & 3.42 & 16.00 & 5.00 & 27.00 & & \\
Back scratch [cm] & SAH & -20.77 & 15.92 & -18.50 & -56.00 & 6.00 & -6.3708 & $<0.001^{*}$ \\
& U3A & -4.60 & 8.71 & -4.00 & -31.00 & 17.00 & & \\
Chair sit-and-reach [cm] & SAH & -9.57 & 11.70 & -10.00 & -36.00 & 10.00 & -6.8703 & $<0.001^{*}$ \\
& U3A & 3.10 & 6.15 & 3.00 & -19.00 & 16.00 & & \\
8 ft up-and-go [s] & SAH & 13.82 & 6.73 & 11.36 & 5.20 & 39.00 & 9.3954 & $<0.001^{*}$ \\
& U3A & 6.57 & 0.93 & 6.60 & 4.56 & 8.75 & & $<0.001^{*}$ \\
6-min walk [m] & SAH & 221.51 & 107.66 & 206.50 & 30.00 & 432.0 & $-9,7570$ & $<$ \\
& U3A & 488.84 & 77.81 & 509.50 & 270.00 & 670.00 & & \\
\hline
\end{tabular}

Z-Mann-Whitney U test, $p-p$ value, ${ }^{*} p \leq 0.05$ 
Table 6 Comparison of the results obtained in different age groups to the normative standards in United States

\begin{tabular}{|c|c|c|c|c|c|}
\hline & \multicolumn{5}{|l|}{ Age groups } \\
\hline & $60-64$ & $65-69$ & $70-74$ & $75-79$ & $80-84$ \\
\hline \multicolumn{6}{|l|}{ Arm curl [reps] } \\
\hline Normative standards & $13-19$ & $12-18$ & $12-17$ & $11-17$ & $10-16$ \\
\hline SAH & 13.95 & 15.50 & 11.60 & 12.21 & 12.05 \\
\hline$\%$ meeting standard & 71.4 & 100 & 70,0 & 71.4 & 76.4 \\
\hline $\mathrm{U} 3 \mathrm{~A}$ & 20.83 & 21.53 & 20.50 & 20.00 & 18.20 \\
\hline$\%$ meeting standard & 100 & 100 & 100 & 100 & 100 \\
\hline \multicolumn{6}{|l|}{ Chair stand [reps] } \\
\hline Normative standards & $12-17$ & $11-16$ & $10-15$ & $10-15$ & $9-14$ \\
\hline $\mathrm{SAH}$ & 10.14 & 11.25 & 9.40 & 8.92 & 8.70 \\
\hline$\%$ meeting standard & 33.3 & 62.5 & 60.0 & 35.7 & 52.9 \\
\hline $\mathrm{U} 3 \mathrm{~A}$ & 19.16 & 16.84 & 15.60 & 14.22 & 14.80 \\
\hline$\%$ meeting standard & 100 & 100 & 100 & 88,8 & 80,0 \\
\hline \multicolumn{6}{|l|}{ Back scratch [cm] } \\
\hline Normative standards & $-3-+1.5$ & $-3.5-+1.5$ & $-4.0-+1.0$ & $-5.0-+0.5$ & $-5.5-0.0$ \\
\hline $\mathrm{SAH}$ & -18.80 & -12.25 & -17.60 & -25.28 & -25.35 \\
\hline$\%$ meeting standard & 14.2 & 37.5 & 20.0 & 7.1 & 23.5 \\
\hline $\mathrm{U} 3 \mathrm{~A}$ & -0.70 & -5.10 & -5.50 & -3.20 & -6.50 \\
\hline$\%$ meeting standard & 66,6 & 50,0 & 30,0 & 44,4 & 60 \\
\hline \multicolumn{6}{|c|}{ Chair sit-and-reach $[\mathrm{cm}]$} \\
\hline Normative standards & $-0.5-+5.0$ & $-0.5-+4.5$ & $-1.0-+4.0$ & $-1.5-+3.9$ & $-2.0-+3.0$ \\
\hline SAH & -8.14 & -10.73 & -12.10 & -10.21 & -8.41 \\
\hline$\%$ meeting standard & 42.8 & 37.5 & 30.0 & 50.0 & 52.9 \\
\hline U3A & 7.30 & 2.90 & 1.40 & 3.80 & 4.4 \\
\hline$\%$ meeting standard & 100 & 87,5 & 70,0 & 100 & 100 \\
\hline \multicolumn{6}{|l|}{$8 \mathrm{ft}$ up-and-go [s] } \\
\hline Normative standards & $6.0-4.4$ & $6.4-4.8$ & $7.1-4.9$ & $7.4-5.2$ & $8.7-5.7$ \\
\hline $\mathrm{SAH}$ & 12.41 & 12.98 & 12.69 & 15.62 & 15.15 \\
\hline$\%$ meeting standard & 4.7 & 0.0 & 0.0 & 7.1 & 11.7 \\
\hline $\mathrm{U} 3 \mathrm{~A}$ & 5.79 & 6.40 & 6.57 & 7.14 & 7.98 \\
\hline$\%$ meeting standard & 50 & 56,2 & 75,0 & 66,6 & 80 \\
\hline \multicolumn{6}{|l|}{ 6-min walk [m] } \\
\hline Normative standards & $498.3-603.5$ & $457.2-580.6$ & $438.9-562.3$ & $393.1-534.9$ & $352-493.7$ \\
\hline $\mathrm{SAH}$ & 240.47 & 225.62 & 253.30 & 193.78 & 208.52 \\
\hline$\%$ meeting standard & 0.0 & 0.0 & 0.0 & 7.1 & 0.0 \\
\hline U3A & 571.41 & 507.21 & 465.57 & 476.38 & 387.6 \\
\hline$\%$ meeting standard & 83.3 & 87.5 & 75.0 & 100.0 & 80.0 \\
\hline
\end{tabular}

Results within the normative standard ranges denoted in bold 
and $80-84$ years groups were above the $50^{\text {th }}$ percentile, whilst the results of the $65-69$ years and $70-74$ years groups were in the $25^{\text {th }}-50^{\text {th }}$ percentile range (Table 7).

When compared with the Polish percentile norms, almost all mean age group scores in the SAH group were below the norms. Only the result of the $65-69$ years group in the arm curl was in the $25^{\text {th }}-50^{\text {th }}$ percentile range. The poorest results were in the 6-min walk, where the average scores in all age groups were below the $10^{\text {th }}$ percentile and in the 8 foot up and go where the average scores in all age groups were above the $90^{\text {th }}$ percentile. The U3A group performed better. In the arm curl, chair stand and 6-min walk the mean results for all age groups were above the $50^{\text {th }}$ percentile. Poorer performance was observed in the 8 foot up, where the average results of the $60-64$ years was in the 50th percentile range, whilst the results of the another age groups were in the $50^{\text {th }}-75^{\text {th }}$ percentile range (Table 8 ).

\section{Evaluation of Polish Older Women's Fitness Levels Relative to Criterion Fitness Standards Associated with Maintaining Physical Independence}

Results of the four Senior Fitness Test assessments used (arm curl, chair stand, 8 foot up and go, and 6-min walk) were compared to the clinically relevant fitness standards that determine the fitness level needed to maintain independence in old age. The SAH group's mean scores did not meet the standards for any of the assessments, and the percentage of women meeting the standards was low. The poorest results were observed for the 8 foot up and go, where the percentage of participants meeting the standards did not exceed $8 \%$, and for the 6 min walk, where no participants met

Table 7 Comparison of the results obtained in different age groups to Portuguese percentile norms

\begin{tabular}{|c|c|c|c|c|c|c|c|c|c|}
\hline \multirow[t]{3}{*}{ SFT Tests } & & \multicolumn{8}{|c|}{ Age groups } \\
\hline & & \multicolumn{2}{|l|}{$65-69$} & \multicolumn{2}{|l|}{$70-74$} & \multicolumn{2}{|l|}{$75-79$} & \multicolumn{2}{|l|}{$80-84$} \\
\hline & & M & Percentil & M & Percentil & M & Percentil & M & Percentil \\
\hline \multirow[t]{2}{*}{ Arm curl [reps] } & $\mathrm{SAH}$ & 15.5 & $25-50$ & 11.60 & $10-25$ & 12.21 & $25-50$ & 12.05 & $50-75$ \\
\hline & U3A & 21.53 & $75-90$ & 20.60 & $50-75$ & 20.00 & $75-90$ & 18.20 & $75-90$ \\
\hline \multirow[t]{2}{*}{ Chair stand [reps] } & SAH & 11.25 & $10-25$ & 9.40 & $10-25$ & 8.92 & $10-25$ & 8.70 & $25-50$ \\
\hline & $\mathrm{U} 3 \mathrm{~A}$ & 16.84 & $50-75$ & 15.60 & $50-75$ & 14.22 & $50-75$ & 14.80 & $75-90$ \\
\hline \multirow[t]{2}{*}{ Back scratch $[\mathrm{cm}]$} & SAH & -12.25 & $25-50$ & -17.60 & $10-25$ & -25.28 & $10-25$ & -25.35 & $10-25$ \\
\hline & U3A & -5.10 & $50-75$ & -5.50 & $50-75$ & -3.20 & $50-75$ & -6.5 & $75-90$ \\
\hline \multirow{2}{*}{$\begin{array}{l}\text { Chair sit-and- } \\
\text { reach }[\mathrm{cm}]\end{array}$} & SAH & -10.73 & $10-25$ & -12.10 & $10-25$ & -10.21 & $25-50$ & -8.41 & $50-75$ \\
\hline & $\mathrm{U} 3 \mathrm{~A}$ & 2.90 & $75-90$ & 1.4 & $50-75$ & 3.8 & $>90$ & 4.4 & $>90$ \\
\hline \multirow[t]{2}{*}{$8 \mathrm{ft}$ up-and-go [s] } & SAH & 12.98 & $<10$ & 12.69 & $<10$ & 15.62 & $10-25$ & 15.15 & $25-50$ \\
\hline & $\mathrm{U} 3 \mathrm{~A}$ & 6.40 & $25-50$ & 6.57 & $25-50$ & 7.14 & $50-75$ & 7.98 & $50-75$ \\
\hline \multirow[t]{2}{*}{ 6-min walk [m] } & SAH & 225.62 & $<10$ & 253.30 & $<10$ & 193.78 & $10-25$ & 208.52 & $25-50$ \\
\hline & U3A & 507.21 & $25-50$ & 465.57 & $25-50$ & 476.38 & $50-75$ & 387.6 & $75-90$ \\
\hline
\end{tabular}

$\mathrm{M}-$ results equal to and higher than 50th percentile denoted in bold 


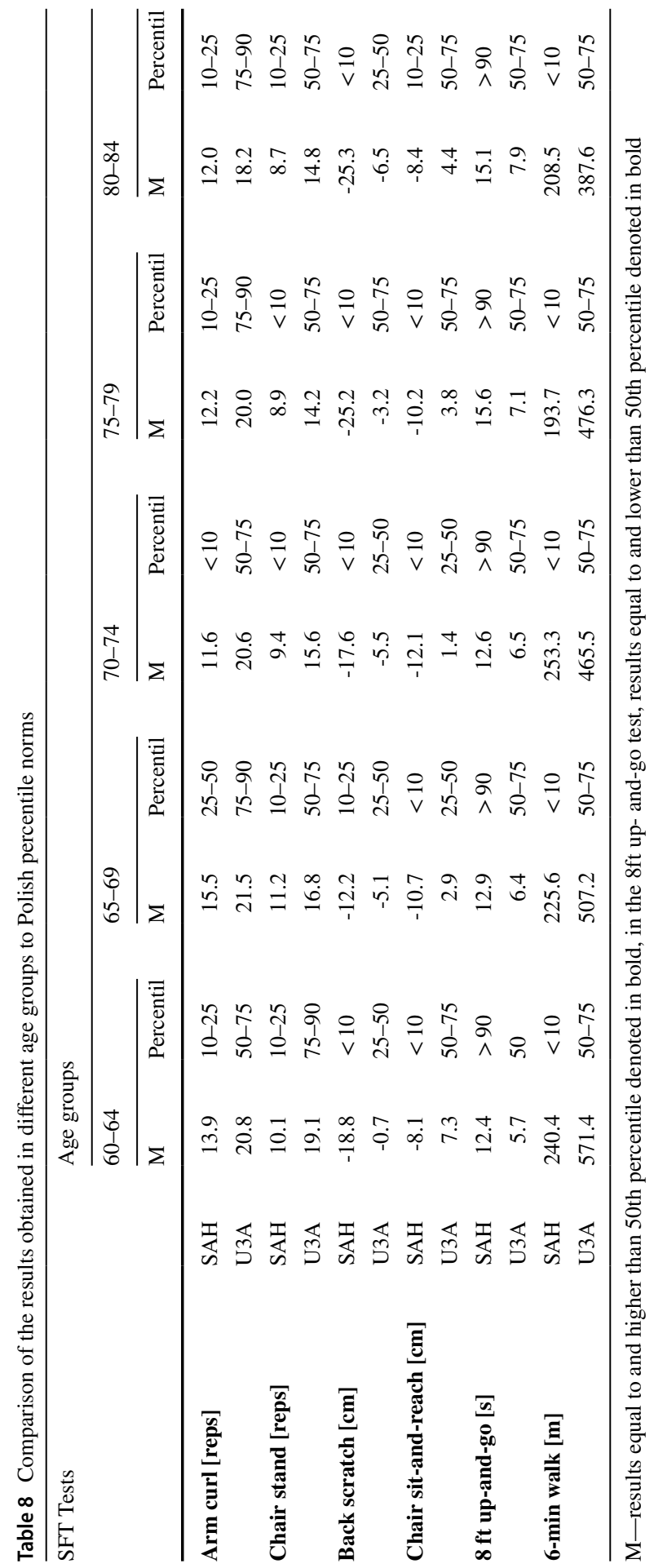


the standards. In the U3A group, the average results for all age groups met the standards for the arm curl and chair stand, and the percentage of participants meeting the standards was high. In the 8 foot up and go and 6-min walk no age group within the U3A group met the standards, and the percentage of women meeting the standards was low (Table 9). In conclusion, the SAH group did not achieve the level of fitness necessary to maintain independence in old age. In the U3A group, only upper and lower body strength levels were sufficient to maintain independence. The level of coordination and dynamic balance was too low to maintain independence.

\section{Discussion}

\section{Key Results and Interpretation}

The first aim of this study was to evaluate and compare the anthropometric characteristics and functional physical fitness of Polish older women from SAH, to that of

Table 9 Comparison with criterion-referenced fitness standards developed by the test authors

\begin{tabular}{|c|c|c|c|c|c|}
\hline & \multicolumn{5}{|c|}{ Age groups } \\
\hline & $60-64$ & $65-69$ & $70-74$ & $75-79$ & $80-84$ \\
\hline \multicolumn{6}{|l|}{ Arm curl [reps] } \\
\hline Fitness standards & 17 & 17 & 16 & 15 & 14 \\
\hline SAH & 13.95 & 15.50 & 11.60 & 12.21 & 12.05 \\
\hline$\%$ meeting standard & 19.0 & 12.5 & 10.0 & 7.1 & 35.2 \\
\hline $\mathrm{U} 3 \mathrm{~A}$ & 20.83 & 21.53 & 20.50 & 20.00 & 18.20 \\
\hline$\%$ meeting standard & 100.0 & 96.8 & 95.0 & 100.0 & 80.0 \\
\hline \multicolumn{6}{|l|}{ Chair stand [reps] } \\
\hline Fitness standards & 15 & 15 & 14 & 13 & 12 \\
\hline SAH & 10.14 & 11.25 & 9.40 & 8.92 & 8.70 \\
\hline$\%$ meeting standard & 4.7 & 25.0 & 30.0 & 14.2 & 17.6 \\
\hline $\mathrm{U} 3 \mathrm{~A}$ & 19.16 & 16.84 & 15.60 & 14.22 & 14.80 \\
\hline$\%$ meeting standard & 100.0 & 81.2 & 75.0 & 77.7 & 100 \\
\hline \multicolumn{6}{|l|}{$8 \mathrm{ft}$ up-and-go [s] } \\
\hline Fitness standards & 5.0 & 5.3 & 5.6 & 6.0 & 6.5 \\
\hline SAH & 12.41 & 12.98 & 12.69 & 15.62 & 15.15 \\
\hline$\%$ meeting standard & 0.0 & 0.0 & 0.0 & 0.0 & 0.0 \\
\hline $\mathrm{U} 3 \mathrm{~A}$ & 5.79 & 6.40 & 6.57 & 7.14 & 7.98 \\
\hline$\%$ meeting standard & 16.6 & 9.3 & 15.0 & 11.1 & 0.0 \\
\hline \multicolumn{6}{|l|}{ 6-min walk [m] } \\
\hline Fitness standards & 571.5 & 553.2 & 530.3 & 502.9 & 466.3 \\
\hline SAH & 240.47 & 225.62 & 253.30 & 193.78 & 208.52 \\
\hline$\%$ meeting standard & 0.0 & 0.0 & 0.0 & 0.0 & 0.0 \\
\hline U3A & 571.41 & 507.21 & 465.57 & 476.38 & 387.6 \\
\hline$\%$ meeting standard & 33.3 & 9.3 & 15.0 & 33.3 & 20.0 \\
\hline
\end{tabular}

Results within the criterion-referenced fitness standards denoted in bold 
Polish older women living independently and taking classes with U3A. The results of the study indicate that the SAH group was characterized by lower physical fitness compared to the U3A group and the women in the SAH group were lighter and shorter than the women in the U3A group. In all assessments that comprise the Senior Fitness Test, the SAH group demonstrated poorer results in comparison to the U3A group. Women living independently, such as those in the U3A group, have to perform their own daily activities. Additionally, the women in the U3A group participated in classes provided by the U3A. In Poland the U3A provides educational and physical activity classes. The most common physical activity classes include gymnastics, swimming, water gymnastics, Nordic walking, and hiking. Living independently and participating in physical activity classes influences the level of older adults' functional fitness. The poorer results obtained by the SAH group may be explained by the lack of participation in everyday activities such as shopping and cooking. Whilst SAH residents participate in rehabilitation classes and occupational therapy, it is possible that not all older adults benefit from such participation, or that participation only provides limited benefits. Consequently, the activity level of older women in SAH is very low. This low level of activity has been confirmed in previous studies. A study by Barber et al. (2015) showed that the physical activity levels of SAH residents were very low and time being sedentary was high. A crosssectional study conducted in German nursing homes found that exercise instructions were not effectively communicated to residents, and that less than half of residents participated in the activities provided (Kalinowski et al., 2012). Furthermore, living in senior housing was inversely associated with physical activity levels (Fisher et al., 2018).

Findings from the present study suggest that older adults' place of residence and living environment can significantly affect their level of functional physical fitness, and that this level of fitness is an important factor in maintaining independence. Higher levels of strength, motoric coordination, dynamic balance, and aerobic capacity can contribute to efficient everyday functioning, fall prevention, and improved quality of life. To achieve and maintain an appropriate level of functional physical fitness provision of systematic physical activity in SAH, and by the U3A, is necessary. Physical activity programs should include the development of strength, endurance, flexibility, dynamic coordination, and balance, as indicated by previous research. A study by Ogonowska-Słodownik et al. (2016) found that the level of functional fitness of active women, participants of U3A gymnastic classes, remained at similar levels in three different age groups. Systematic motoric rehabilitation classes for older women in SAH improved levels of physical fitness and aerobic capacity compared to SAH residents not attending rehabilitation classes (Fortuna et al., 2017). In addition to improvements in functional physical fitness, physical activity programs for those living in SAH have also increased residents' social engagement [Raynor et al., 2019; Arrieta et al., 2018; Marmeleira et al., 2018].

Other studies investigating the fitness and activity levels of nursing home residents and women living independently in Poland have been carried out. A study by Ignasiak et al. (2009) found that older age and living in an institution significantly lowered older adults' fitness levels. Participants living in an institution demonstrated significantly lower levels of fitness compared to those living independently 
(Ignasiak et al., 2009). Another study of SAH female residents found that participants met the USA normative standards for strength and endurance (Kaczorowska et al., 2013). A study by Leś and Gaworska (2011) found that the women living in SAH were characterized by lower functional fitness compared to the women attending daytime homes. Ignasiak et al. (2017) also conducted an extensive study investigating the functional fitness and physical activity of older adults from Dolnośląskie province. The study included 431 women and 125 men, and used the Senior Fitness Test to assess fitness levels. The results of four tests obtained from particular age groups were compared to the USA normative standards. For women, the results of the 8 foot up and go and 6-min walk were similar to normative standards, with $67 \%$ and $53 \%$ respectively achieving results within the relevant range. Lower percentages were observed for the arm curl and chair stand, with $23 \%$ and $28 \%$ respectively achieving results within the relevant range. Participants in this study were members of senior clubs, and U3A students. Lower levels of strength were possibly a result of the lack of physical activity in senior clubs.

After the American Senior Fitness Test standards were developed, due to the social, economic, and cultural differences between societies, scientists began to create norms for the peoples of their countries. Such norms were developed in Portugal in 2014 (Marques et al., 2014) and in Poland in 2020 (Ignasiak et al., 2020). When comparing the results of the present study to the USA normative standards and Portuguese percentile norms, it was observed that a large percentage of women in the U3A group met the standards, and that the average results of the U3A group were within the appropriate range of these standards. The U3A group performed well in comparison to Portuguese women. In most tests the mean results of Polish women exceeded the $50^{\text {th }}$ percentile of Portuguese norms. When comparing the results the U3A group to Polish percentile norms, main scores of tests assessing upper and lower body strength and aerobic capacity were above the $50^{\text {th }}$ percentile. The tests assessing the flexibility of the upper and lower body as well as coordination and dynamic balance were weaker. However, the functional physical fitness of the SAH group was poorer in comparison to American, Portuguese and Polish women. The poorer results observed for coordination and dynamic balance, and aerobic capacity, are concerning. Good coordination and balance, along with a higher aerobic capacity, can help older adults to be self-reliant and live independently. Moreover, good coordination and balance can help reduce the risk of falls. Poor results were also observed for upper body flexibility and mobility. Upper body flexibility and mobility is important for grasping and reaching, and everyday activities such as unassisted dressing. Polish norms have been developed for seniors living independently, so they may be too high for residents of social homes.

In 2012, Rikli and Jones developed clinically relevant fitness standards for older adults, in an attempt to define the level of fitness necessary to maintain independence in old age. These standards utilized four assessments from the Senior Fitness Test (arm curl, chair stand, 8 foot up and go, and 6-min walk) to assess upper and lower body strength, coordination and dynamic balance, and aerobic capacity. Older adults whose results are within the fitness standards can function independently (Rikli \& Jones, 2012). A large percentage of the participants in the present study, including those living independently, did not achieve the clinically relevant fitness 
standards. Therefore, it is important to assess the fitness of both older adults in SAH and those living independently to identify areas of reduced physical capacity, and to introduce physical activity programs to address these areas. Moreover the fitness standards were developed for American society, and therefore may not be applicable to Polish society.

The participants in the present study came from the Dolnośląskie and Opolskie provinces, and were born between 1931 and 1959 (i.e., between World Wars I and II, during World War II, or during the immediate post World War II period). It is possible that adverse environmental conditions early in life may predispose some individuals to the later development of degenerative diseases (Baker, 2001). Stress connected with living during war, or during challenging and adverse conditions post war, may predispose some people to various diseases. Moreover the USA is a country with completely different economic, social and cultural conditions than Poland. Whilst Poland and Portugal are European countries, there are social and cultural differences between the two countries that may affect older adults' physical fitness. This is why a country's standards are so important in assessing the fitness of its residents, including seniors. Therefore, due to the social, economic, and cultural differences between American and Polish societies, it would be appropriate to develop Polish clinically relevant fitness standards for the Senior Fitness Test.

There are a limited number of studies that have investigated differences in anthropometric characteristics and functional physical fitness between older adults living in different environments in Poland. Therefore, it is appropriate to investigate older adults living in different environments.

\section{Limitations}

The present study has some limitations. Only women were included in the investigation. Men live shorter than women, but are characterized by a greater level of physical activity. Moreover, fewer men than women live in social welfare homes. Perhaps, this is due to the higher male mortality causing more older women to be single and choose or have to live in a social welfare home. Therefore, future research should consider the impact of different living environments on the anthropometric characteristics and functional physical fitness of older men in Poland. Next limitations of the study relate to whether the sample of older adults in SAH group and U3A group represents older adults in the population. The study groups may not be representative of all SAH residents and U3A participants. In addition, the study does not allow conclusions regarding causality. Consideration should be given to longitudinal studies with several points of measurement, as this would allow tracking and correction for changes in functional physical fitness and also allow more insight into the relationship between physical fitness, age and different environments. Additionally, as the research was performed in only two Polish provinces, it would be beneficial for future research to investigate the impact of different living environments on older adults in other Polish provinces. 


\section{Conclusion}

(1) Independent living and the physical activity connected with the classes provided by the U3A influenced older adults' levels of functional physical fitness.

(2) The level of functional fitness of Polish residents of social assistance homes is insufficient to maintain independence in old age. Various physical activity and occupational therapy programs should be introduced.

(3) Due to the social, economic, and cultural differences between societies, a country's standards should be used in assessing the functional fitness of its population.

Acknowledgements There were no other contributors to the article than the authors as well as there was no writing assistance regarding our paper. We would like to thank the patients for their contribution in this research.

Author Contribution All authors of this manuscript meet the authorship criteria according to the latest guidelines of the International Committee of Medical Journal Editors (ICMJE), as well as all authors have seen and approved the manuscript being submitted and published. All authors contributed to the study conception and design. Material preparation, data collection were performed by Antonina Kaczorowska, Małgorzata Fortuna, Aleksandra Katan and Agnieszka Kaczorowska. Analysis was performed by Antonina Kaczorowska, Małgorzata Fortuna and Zofia Ignasiak. The first draft of manuscript was written by Antonina Kaczorowska and all authors commented on previous version of the manuscript. All authors read and approved the final manuscript.

Funding This research did not receive any specific grant from funding agencies in the public, commercial, or not-for-profit sectors.

Availability of Data and Material All the data can be assessed by reasonable request from the corresponding author.

\section{Declarations}

Ethics Approval The Commission of Research of the University School of Physical Education, Wrocław, Poland granted approval for the research (approval date: 2015).

Consent to Participate All participants gave written informed consent to participate in the study after explanation of the procedures involved.

Conflict of Interest The authors have no relevant financial or non-financial interests to disclose.

Open Access This article is licensed under a Creative Commons Attribution 4.0 International License, which permits use, sharing, adaptation, distribution and reproduction in any medium or format, as long as you give appropriate credit to the original author(s) and the source, provide a link to the Creative Commons licence, and indicate if changes were made. The images or other third party material in this article are included in the article's Creative Commons licence, unless indicated otherwise in a credit line to the material. If material is not included in the article's Creative Commons licence and your intended use is not permitted by statutory regulation or exceeds the permitted use, you will need to obtain permission directly from the copyright holder. To view a copy of this licence, visit http://creativecommons.org/ licenses/by/4.0\%. 


\section{References}

Arrieta, H., Rezola-Pardo, C., Zarrazquin, I., Echeverria, I., Yanguas, J. J., Iturburu, M., Gil, S. M., Rodriguez-Larrad, A., \& Irazusta, J. (2018). A multicomponent exercise program improved physical function in long-term nursing home residents: A randomized controlled trial. Experimental Gerontology., 103, 94-100. https://doi.org/10.1016/j.exger.2018.01.008

Auyeung, T. W., Lee, J. S., Kwok, T., \& Woo, J. (2011). Physical frailty predicts future cognitive decline - a four-year prospective study in 2737 cognitively normal older adults. The Journal of Nutrition, Health \& Aging., 15(8), 690-694.

Baker, D. J. (2001). A new model for the origins of chronic disease. Medicine, Health Care and Philosophy., 4, 31-35. https://doi.org/10.1023/a:1009934412988

Barber, S. E., Forster, A., \& Birch, K. M. (2015). Levels and Patterns of Daily Physical Activity and Sedentary Behavior Measured Objectively in Older Care Home Residents in the United Kingdom. Journal of Aging and Physical Activity., 23(1), 133-143. https://doi.org/10.1123/japa.2013-0091

Central Statistical Office. (2016). Population aged 60+. [Demographic structure and health]. Warszawa. [accessed 2020 Sep 22]. http://www.stat.gov.pl. Polish.

Central Statistical Office. (2021). Population status and structure as well as population movement in a territorial section. Warszawa. [accessed 2021 Oct 20]. http://www.stat.gov.pl. Polish.

Fisher, K. L., Harrison, E. L., Bruner, B. G., Lawson, J. A., Reeder, B. A., Ashworth, N. L., Sheppard, M. S., \& Chad, K. E. (2018). Predictors of Physical Activity Levels in Community-Dwelling Older Adults: A Multivariate Approach Based on a Socio-Ecological Framework. Journal of Aging and Physical Activity., 26(1), 114-120. https://doi.org/10.1123/japa.2016-0286

Fortuna, M., Kaczorowska, A., Szczurowski, J., Katan, A., Radajewska, A., \& Demczyszak, I. (2017). Significance of rehabilitation in the assessment of the level of oxygen efficiency and effectiveness of the social assistance centres. Polish Journal of Physiotherapy., 17(3), 90-95.

Gaigaliene, B., Ceremnych, E., Alekna, V., Filipaviciute, R., \& Saplinskas, J. (2006). The sociodemographic situation, health and physical functions of very elderly cohort in Vilnius (Lithuania). Antropomotoryka., 33, 27-33.

Ignasiak, Z., Kaczorowska, A., Katan, A., \& Domaradzki, J. (2009). Evaluation of fitness of elderly women by means of Fullerton Test. Physiotherapy, 17(2), 48-52.

Ignasiak z, Sebastjan A, Sławińska T, Skrzek A, Czarny W, Król P, et al. (2020). Functional fitness normative values for elderly polish population. BMC Geriatrics., 20, 384. https://doi.org/10.1186/ s12877-020-01787-2

Ignasiak, Z., Sławińska, T., Skrzek, A., Rożek, K., Kozieł, S., Posłuszny, P., \& Malina, R. M. (2017). Functional Capacities of Polish Adults of 60-87 Years and Risk of Losing Functional Independence. Annals of Human Biology., 40(6), 502-509. https://doi.org/10.1080/03014460.2017.1328071

Kabsch, A. (2001). Disablement following ageing processes - a challenge to physiotherapy. Physiotherapy, 9(3), 3-19.

Kaczorowska, A., Katan, A., \& Ignasiak, Z. (2013). Evaluation of physical fitness of elderly women, residents of houses of social services. Physiotherapy, 21(4), 17-27.

Kalinowski, S., Wulff, I., Kölzsch, M., Kopke, K., Kreutz, R., \& Dräger, D. (2012). Physical Activity in Nursing Homes - Barriers and Facilitators: A Cross-Sectional Study. Journal of Aging and Physical Activity., 20(4), 421-441. https://doi.org/10.1123/japa.20.4.421

Karlin, N. J., \& Weil, J. (2017). Healthy Aging in a Global Context: Comparing Six Countries. Ageing International., 42, 1-22.

Leś, A., \& Gaworska, M. (2011). Quality of life and functional fitness of the elderly. Biomedical Human Kinetics., 3, 57-60. https://doi.org/10.2478/v10101-011-0013-6

Marmeleira, J., Galhardas, L., \& Raimundo, A. (2018). Exercise merging physical and cognitive stimulation improves physical fitness and cognitive functioning in older nursing home residents: A pilot study. Geriatric Nursing., 39(3), 303-309. https://doi.org/10.1016/j.gerinurse.2017.10.015

Marques, E. A., Baptista, F., Santos, R., Vale, S., Santos, D. A., Silva, A. M., Mota, J., \& Sardinha, L. B. (2014). Normative Functional Fitness Standards and Trends of Portuguese Older Adults: Cross Cultural Comparisons. Journal of Aging and Physical Activity, 22(1), 126-137. https://doi.org/10. 1123/japa.2012-0203

Maslow, A. L., Price, A. E., Sui, X., Lee, D. C., Vuori, I., \& Blair, S. N. (2011). Fitness and adiposity as predictors of functional limitation in adults. Journal of Physical Activity and Health., 8(1), 18-26. https://doi.org/10.1123/jpah.8.1.18 
Milanović, Z., Pantelić, S., Trajković, N., Sporis, G., Kostic, R., \& James, N. (2013). Age-related decrease in physical activity and functional fitness among elderly men and women. Clinical Interventions in Aging., 8, 549-556. https://doi.org/10.2147/CIA.S44112

Ogonowska-Słodownik, A., Bober, E. M., \& Molik, B. (2016). Functional fitness and body composition of active older women in different age categories. Advances in Rehabilitation., 1, 11-17.

Olivares, P. R., Gusi, N., Prieto, J., \& Hernandez-Mocholi, M. A. (2011). Fitness and health-related quality of life dimensions in community-dwelling middle aged and older adults. Health and Quality of Life Outcomes., 9, 117. https://doi.org/10.1186/1477-7525-9-117

Rava, A., Pihlak, A., Ereline, J., Gapeyeva, H., Kums, T., Purge, P., Jürimäe, J., \& Pääsuke, M. (2017). Body Composition, Neuromuscular Performance, and Mobility: Comparison Between Regularly Exercising and Inactive Older Women. Journal of Aging and Physical Activity., 25(1), 58-64. https://doi.org/10.1123/japa.2016-0019

Raynor, A. J., Iredale, F., Crowther, R., White, J., \& Dare, J. (2019). It's Not Just Physical: Exercise Physiologist-Led Exercise Program Promotes Functional and Psychosocial Health Outcomes in Aged Care. Journal of Aging and Physical Activity., 28(1), 104-113. https://doi.org/10.1123/japa. 2019-0088

Rikli, R. E., \& Jones, C. J. (1999). Development and validation of a functional fitness test for communityresiding older adults. Journal of Aging and Physical Activity., 7, 129-161.

Rikli, R., \& Jones, J. (2001). Senior Fitness Test Manual. Human Kinetics.

Rikli, R., Jones, J. (2002). Measuring functional fitness of older adults. Journal of Active Aging. MarchApril: 23-30.

Rikli, R., \& Jones, J. (2012). Development and Validation of Criterion-Referenced Clinically Relevant Fitness Standards for Maintaining Physical Independence in Later Years. The Gerontologist., 53(2), 255-267. https://doi.org/10.1093/geront/gns071

São Romão Preto, L., Nogueiro Santos A. L., Mendes, M. E., Pinto Novo, A., Pimentel, M. H. (2015). Functional impairment, fear of falling and body composition in institutionalized elderly. Enfermeria Clinica. 25(2):81-86. [article in Spanish]. https://doi.org/10.1016/j.enfcli.2014.10.005

Skrzek, A., Ignasiak, Z., Sławińska, T., Domaradzki, J., Fugiel, J., Sebastjan, A., \& Rożek, K. (2015). Structural and functional markers of health depending on lifestyle in elderly women from Poland. Clinical Interventions in Aging., 10, 781-793. https://doi.org/10.2147/CIA.S79485

Publisher's Note Springer Nature remains neutral with regard to jurisdictional claims in published maps and institutional affiliations.

Antonina Kaczorowska Education 2007 - 2010 - Doctoral studies at the University School of Physical Education in Wrocław (Poland); 1990 - 1994 - studies at the University School of Physical Education in Wrocław (Poland). Postgraduate studies Qualifying Pedagogical Course 2011; Postgraduate studies "Organisation of social assistance" 2010; Postgraduate studies " Healthcare management " 2003. Professional experience 2020 - at present: lecturer at the Institute of Health Sciences, University of Opole (Poland); 2012 - 2020: lecturer at the Physiotherapy Department, Opole Medical School (Poland); 2004 - 2017: lecturer at the Department of Social Sciences and Health in the field of Physiotherapy at the Wałbrzych University of Management and Entrepreneurship (Poland); 1997 - 2009 : Physiotherapist at the Country Nursing Home in Ostrowina (Poland); 1995 - 1996 : Physiotherapist in the Hohenfeld Pitzer Clinic in Bad Camberg (Germany). Main research directions Research directions - gerontology, physiotherapy in geriatrics, activity and physical fitness of people of different ages. Author of several dozen articles in scientific journals. Active participant of many scientific conferences. Membership and activity in associations Member of the Polish Society of Physiotherapy. 